\title{
A Study of Two Marine Agar-Decomposing, Facultatively Anaerobic Myxobacteria
}

\author{
BY H. VELDKAMP \\ Microbiological Laboratory, Agricultural University, \\ Wageningen, Netherlands
}

(Received 19 April 1961)

\section{SUMMARY}

Two facultatively anaerobic agar-decomposing myxobacteria were isolated from marine mud and described as Cytophaga fermentans Bachmann var. agarovorans var. nov. and $C$. salmonicolor var. agarovorans var. nov. A third organism which does not attack agar was isolated from the same source; it has been included in the present study for comparative purposes. The specific name Cytophaga salmonicolor has been given to this organism. All organisms are characterized by exhibiting flexing and gliding motility and by absence of microcysts and fruiting bodies. The organisms can be grown in a mineral glucose medium, although growth is accelerated and more abundant when a vitamin mixture is included in the medium. $\mathrm{CO}_{2}$ is an absolute requirement for growth. Growth of $C$. fermentans var. agarovorans and C. salmonicolor var. agarovorans on aerobic plate cultures is markedly inhibited by $0.1 \%$ glucose or galactose. Acetic, propionic and succinic acids are major end products of sugar fermentation of all three types. C. salmonicolor and C. salmonicolor var. agarovorans form in addition $\mathrm{CO}_{2}$ and $\mathrm{H}_{2}$, and small amounts of lactic and formic acids and ethanol.

\section{INTRODUCTION}

Agar, obtained by hot water extraction of marine Rhodophyta (Mori, 1953), contains two polysaccharides, agarose and agaropectin (Araki, 1956). The latter, a minor constituent, is a rather complex substance, comprising sulphuric and uronic acid components. The major constituent, agarose, seems to consist of alternately repeated units of 1:3-linked $\beta$-D-galactopyranose and 1:4-linked 3:6-anhydro- $\alpha$-Lgalactopyranose; it can be enzymically hydrolysed to neo-agarobiose, which is composed of D-galactose and 3:6-anhydro-L-galactose (Araki \& Arai, 1956; Yaphe, 1957).

Although several kinds of agar-decomposing bacteria have been isolated from soil, such organisms represent only a very small fraction of the soil microflora; hence they are rarely encountered by the soil microbiologist. On the other hand, agar-digesting bacteria are common in marine environments. Undoubtedly this is due to the wide distribution and abundance of agar-containing seaweeds. Humm (1946), studying the marine agar-decomposing bacteria of the South Atlantic coast of the U.S.A., reported that the intertidal zone of the beaches contains 2-20 million agardigesting bacteria per gram; as determined by plate counts, they represent $2-4 \%$ of the total number of aerobic bacteria in this zone.

Among the 20 agar-decomposing bacteria Humm (1946) describes is Cytophaga 
sensitiva, isolated directly from decaying marine algae. Stanier (1941) had previously discovered two other agar-decomposing cytophagas, C. krzemieniereskae and C. diffluens; these had been found on seawater count plates. These three cytophagas are strict aerobes. Bachmann (1955) was the first to describe a facultatively anaerobic cytophaga, C. fermentans. It produces craters and gelase fields on seawater agar plates with $1 \%(\mathrm{w} / \mathrm{v})$ yeast extract, but does not grow in media containing agar as sole energy source, even if they are adequate for growth when supplemented with a fermentable sugar. And, because galactose is also unsuitable as a carbon source for this bacterium, Bachmann (1955) concluded that it cannot be considered as a genuine agar-decomposer in the sense of an organism that can grow at the expense of agar. Anderson \& Ordal (1961a) described another facultatively anaerobic cytophaga, C. succinicans, which was isolated from fresh water.

In 1947 and 1948, Drs S. R. Elsden and H. Larsen, respectively, isolated facultatively anaerobic cytophagas, which rapidly decompose agar and produce a pink pigment, from elective cultures of green sulphur bacteria at the Hopkins Marine Station of Stanford University, Pacific Grove, California, U.S.A. A similar organism was isolated in 1958 by $\mathrm{Dr}$ K. Eimhjellen in the same laboratory (Dr C. B. van Niel, personal communication). The facultatively anaerobic cytophagas described in the present paper were isolated in the same institution by Dr June Lascelles, who noticed their incidental occurrence in crude cultures of purple sulphur bacteria. She also showed, as had previously been done by Elsden, that such organisms can be more specifically enriched by using anaerobic cultures with media in which agar represents the sole carbon and energy source.

\section{RESULTS}

\section{Isolation and maintenance}

The medium used for the elective cultures contained, per $100 \mathrm{ml} \mathrm{H}_{2} \mathrm{O}: \mathrm{NaCl}, 3 \mathrm{~g}$; ; $\mathrm{KH}_{2} \mathrm{PO}_{4}, 0.1 \mathrm{~g}$; $\mathrm{NH}_{4} \mathrm{Cl}, 0 \cdot 1 \mathrm{~g}$.; $\mathrm{MgCl}_{2} .6 \mathrm{H}_{2} \mathrm{O}, 0.05$ g.; $\mathrm{CaCl}_{2}, 0.004$ g.; $\mathrm{NaHCO}_{3}$, 0.5 g.; $\mathrm{Na}_{2} \mathrm{~S} .9 \mathrm{H}_{2} \mathrm{O}, 0.01$ g.; Fe-citrate, $\mathrm{M} / 250,0.5 \mathrm{ml}$; trace element mixture, $0.2 \mathrm{ml}$.; powdered agar, $0.5 \mathrm{~g}$.; Difco yeast extract, $0.03 \mathrm{~g}$; adjusted to $\mathrm{pH} \mathbf{7 \cdot 0}$. The trace element mixture used was that of Kohlmiller \& Gest (1951).

Bottles, completely filled with this medium, were inoculated with marine mud from areas with decayed algae, stoppered, and incubated in the dark at $30^{\circ}$. After 3-5 days, anaerobic plate or shake cultures were prepared, using the above medium with $2 \%(\mathrm{w} / \mathrm{v})$ agar; the shake cultures were covered with paraffin to maintain anaerobiosis.

Colonies which on microscopic examination exhibited the flexing movements characteristic of myxobacteria were further purified by the shake culture method.

The isolates were maintained as paraffin-covered stab cultures in the elective culture medium with $1 \%(\mathrm{w} / \mathrm{v})$ agar, supplemented with $0.1 \%(\mathrm{w} / \mathrm{v})$ glucose for Cytophaga salmonicolor and as anaerobic liquid cultures in Hall tubes as modified by Barker (1936) in such a medium in which the agar was replaced by $0 \cdot 1 \%(\mathrm{w} / \mathrm{v})$ glucose, galactose or starch. The cultures were incubated at $30^{\circ}$ for $2-3$ days, and thereafter stored at $4^{\circ}$; transfers were made monthly.

For aerobic plate and semi-anaerobic stab cultures a modified agar medium was used; it contained only $0.05 \% \mathrm{NaHCO}_{3}$, no $\mathrm{Na}_{2} \mathrm{~S}$, and $0.1 \%$ each of yeast extract, corn steep liquor, and dehydrated nutrient broth. 


\section{Growth requirements}

All three strains grew equally well anaerobically in the liquid medium when the yeast extract was replaced by a mixture of pyridoxin, riboflavin, thiamine, nicotinamide, pantothenic acid, folic acid and $p$-aminobenzoic acid, each at $0.4 \mathrm{mg}$./l.; biotin, $0.04 \mathrm{mg}$. $/ \mathrm{l}$; and cyanocobalamine, $0.002 \mathrm{mg}$./l. They may also grow in a vitamin-free glucose medium; but here growth is far less copious and sometimes erratic, particularly in the case of semi-anaerobic cultures of Cytophaga fermentans var. agarovorans. In contrast, aerobic cultures did not develop on chemically defined media. C. fermentans var. agarovorans and C. salmonicolor var. agarovorans, which both decomposed agar extensively under anaerobic conditions, grew at best sparsely

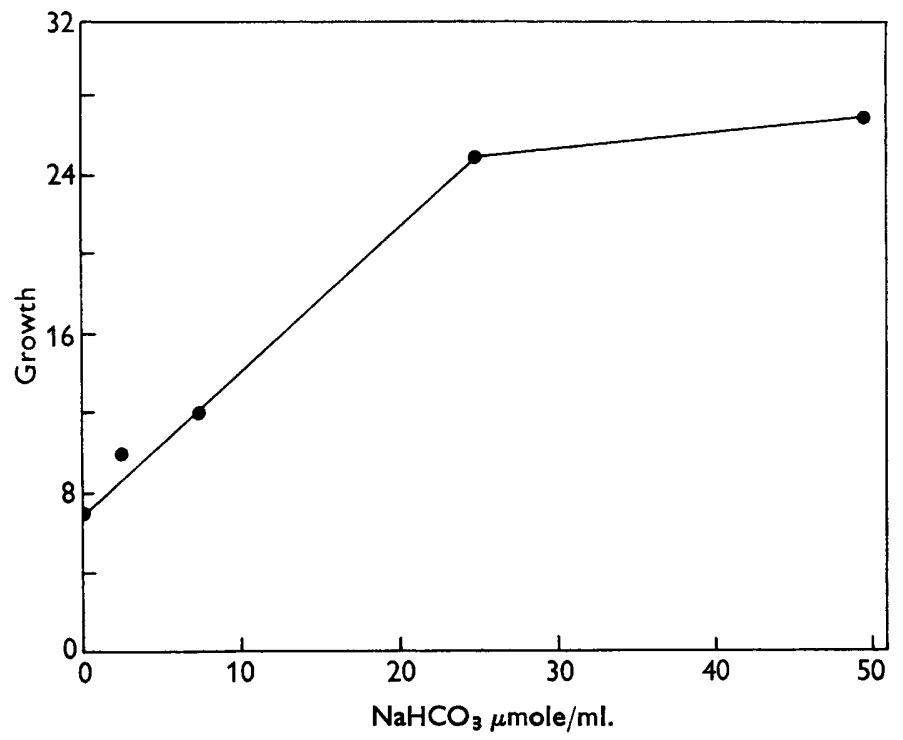

Fig. 1. Growth of Cytophaga fermentans var. agarovorans in mineral medium with $0 \cdot 1 \%$ $(\mathrm{w} / \mathrm{v})$ mannitol $+0.03 \%(\mathrm{w} / \mathrm{v})$ yeast extract at different $\mathrm{NaHCO}_{3}$ concentrations. Turbidity measured after cultivation for 2 days by Eel colorimeter. Data provided by Dr June Lascelles.

on a $1 \%(w / v)$ agar medium with $0.1 \%(w / v)$ yeast extract. However, when this medium was supplemented with corn steep liquor and nutrient broth, these organisms grew well and formed deep craters in the agar solidified medium, showing that they digested agar aerobically also.

Bachmann (1955) observed a similar phenomenon with Cytophaga fermentans. Anaerobically this organism required thiamine as the only growth factor; but it did not grow aerobically unless $1 \%(\mathrm{w} / \mathrm{v})$ yeast extract was added. Then growth was accompanied by a softening of the agar and the appearance of shallow craters and gelase fields. In the absence of air this species did not grow with agar as sole C source.

Additional information about growth of our organisms on agar will be found below. A wide variety of carbohydrates is fermented by these organisms; they are listed under the respective species descriptions. The $\mathrm{pH}$ optimum for growth is about 
7-7.5; fermentation ceased when the $\mathrm{pH}$ value decreased to $\mathbf{5 \cdot 5}$, after which the cultures became non-viable within a week. All strains grew rapidly at temperatures between $28^{\circ}$ and $37^{\circ}$. Growth under anaerobic conditions was very poor when $\mathrm{NaHCO}_{3}$ was omitted from the medium; Fig. 1 shows the effect of different $\mathrm{NaHCO}_{3}$ concentrations. It is evident that an optimal response was reached at a concentration of about $0.3 \%$. For these experiments a heavily buffered medium was used; hence it seems unlikely that the bicarbonate exerted its influence by regulating the $\mathrm{pH}$ value of the medium. Because our cytophagas carry out a propionic acid fermentation, which in other cases has been shown to involve carboxylation reactions, it seems far more probable that a fairly high $\mathrm{CO}_{2}$ tension is required for metabolic activity. If $\mathrm{CO}_{2}$ were also indispensable for aerobic growth, the need to supplement agar media with yeast extract, corn steep liquor and nutrient broth may be explained by postulating that on such enriched media an adequate $\mathrm{CO}_{2}$ tension is produced locally. This opinion is supported by the fact that aerobic growth of the cytophagas may occur at the expense of the complex nitrogenous compounds alone; but the addition of a fermentable carbohydrate speeds up and enhances the development.

The fermentation of glucose by Cytophaga succinicans also appears to be $\mathrm{CO}_{2^{-}}$ dependent (Anderson \& Ordal, 1961 b). From their experiments with this organism these authors concluded that ' $\mathrm{CO}_{2}$ functions in the fermentation by providing, through condensation with phosphoenolpyruvate, compounds which can serve as acceptors for the available hydrogen generated in glucose degradation.'

Nitrates, ammonium salts, yeast extract, nutrient broth, and Casamino acids also can serve as nitrogen source for our cytophagas.

All strains grew well in media with $1-3 \%(\mathrm{w} / \mathrm{v}) \mathrm{NaCl}$; very little growth occurred at lower $\mathrm{NaCl}$ concentrations.

\section{Morphology}

Our cytophagas could not be differentiated on the basis of their morphology. The organisms of all strains were slender with rounded ends (Pl. 1, fig. 5); they were extremely flexible and weakly refractile, and exhibited gliding movements, often alternately forwards and backwards. These movements were generally rather slow and regular, although sometimes sudden 'jumps' were observed. In wet mounts the cells were often seen to move against currents in the liquid. Organisms embedded in agar were generally much coiled. These organisms cannot be considered as involution forms since they straightened out and often appeared to be actively motile when forced into liquid channels surrounding the agar in wet mounts.

The organisms varied from 2 to $30 \mu$ in length; occasionally very long elements, up to $50 \mu$ long were seen. These long organisms, which also occurred in young cultures often showed flexing and gliding movements. The average length of organisms grown aerobically on agar plates was usually greater than that of organisms from stab or anaerobic liquid cultures. Short cells (about $3 \mu$ long) did not show flexibility. They were never found to predominate, however, as they do in cultures of Cytophaga johnsonae (Stanier, 1947). Branched cells were never observed in our cultures. Fruiting bodies were not observed, nor were microcysts. Thus our strains are typical representatives of the genus Cytophaga as defined by Stanier (1942).

In cultures which had reached the stationary growth phase, spherical organisms 
(Pl. 1, fig. 6) were always found. They varied in diameter from 1 to $3.5 \mu$, and small round bodies or rod-like structures could usually be seen within these organisms. Rod-shaped organisms with a spherical extrusion also frequently occurred in these cultures.

The fact that the spherical cells varied considerably in diameter, as well as the observation that they were formed when cultures were about to lose their viability, makes it seem unlikely that they were microcysts as formed in the genus Sporocytophaga. Bachmann (1955) reached similar conclusions about the round bodies she observed in aged cultures of Cytophaga fermentans. Coccoid involution forms were also found in cultures of C. hutchinsonii and C. krzemieniewskae (Stanier, 1942) and $C$. succinicans (Anderson \& Ordal, 1961 $a$ ). Spherical bodies reminiscent of those encountered in the Cytophaga cultures have also been found in Treponema zuelzerae (Veldkamp, 1960). Attempts to show the viability of these spherules failed. The transformation into spherical bodies in dying organisms might be a common characteristic of organisms which lack a rigid cell wall.

\section{Growth on agar media}

Anaerobic growth. Plate 1, fig. 1, shows large spherical colonies of Cytophaga fermentans var. agarovorans developing in an agar shake culture (1\% agar, $0 \cdot 1 \%$ yeast extract.) The organisms in these cream-coloured colonies were embedded in the softened agar. In the clear zone which surrounded the colonies the agar was softened by extracellular enzymic activity. C. salmonicolor var. agarovorans produced pink colonies of similar shape; the area occupied by these colonies consisted of completely liquefied agar. The shape of the colonies was not influenced by the inclusion of $0.1 \%(\mathrm{w} / \mathrm{v})$ galactose in the medium; but the colonies were then slightly more dense.

Cytophaga salmonicolor grew very poorly in the above medium unless cornsteep liquor and nutrient broth were added $(0 \cdot 1 \%, \mathrm{w} / \mathrm{v}$, each); spherical, pinkish colonies were then formed which never exceeded 1-2 mm. in diameter (Pl. 1, fig. 2). Softening of the agar was not observed. The addition of glucose or galactose to the medium yielded denser spherical or disk-shaped salmon-coloured colonies of the same size.

Stab cultures of Cytophaga fermentans var. agarovorans and C. salmonicolor var. agarovorans in a medium with $1 \%$ agar and $0.1 \%$ yeast extract are illustrated in Pl. 1, figs. 3, 4. Growth gradually spread outward from the inoculated region, as it did in the case of a colony developing in an agar shake culture (Pl. 1, fig. 1). This is attributable to the softening ( $C$. fermentans var. agarovorans) or liquefaction $(C$. salmonicolor var. agarovorans) of the agar, which permits the cells to migrate. Thus the periphery of a growing colony or stab culture often appears as a diffuse area of low optical density, representing the zone of migration. In media with $2 \%(\mathrm{w} / \mathrm{v})$ agar the tendency to spread was considerably decreased. In stab cultures of $C$. fermentans (ATCC no. 12470) and C. salmonicolor the migration of organisms was limited to a distance of 1-2 mm. from the line of inoculation when $1-1.5 \%(\mathrm{w} / \mathrm{v})$ agar was used; decomposition of agar was not observed.

\section{Aerobic growth}

As stated above, all strains grew copiously under aerobic conditions on a mineral medium containing $1 \%(\mathrm{w} / \mathrm{v})$ agar and $0 \cdot 1 \%(\mathrm{w} / \mathrm{v})$ each of yeast extract, corn steep 
liquor or nutrient broth. Cytophaga fermentans var. agarovorans formed greyish to pale yellow colonies which attained a diameter of about $3 \mathrm{~cm}$. on sparsely seeded plates. The colonies formed deep depressions in the agar and were surrounded by a zone in which the agar became translucent, softened, and generally slightly depressed (Pl. 2, fig. 8). On flooding the plate with a I + KI solution (a test devised by Gran, 1902) this zone remained unstained (Pl. 2, fig. 9). Colonies of C. fermentans var. agarovorans which developed on the above medium were largely subsurface, and generally had a sharp even edge. Occasionally swarming growth across the agar surface was observed, although this was generally limited to small sections of a colony. On media with $2 \%(\mathrm{w} / \mathrm{v})$ instead of $1 \%$ agar, where the penetration of the organisms into the agar was impeded, growth occurred as flat spreading colonies, crater formation was less rapid and the depressions remained very shallow. The influence of agar concentration on the extent of penetration was reminiscent of Stanier's (1947) observations with C. johnsonae.

Cytophaga fermentans var. agarovorans tended to produce colonial variants. Two such variants were encountered: one formed relatively small bright yellow colonies of the sunken type; the other formed small raised pale yellow colonies, which hardly affected the structure of the agar. Swarming motility across an agar surface was never observed with these variant strains. The organisms in the aberrant colonies were morphologically similar to those of the parent strain. Similar variations in colony type were observed by Bachmann (1955) with C.fermentans. When grown on a medium containing $1 \%(\mathrm{w} / \mathrm{v})$ agar, $C$. salmonicolor var. agarovorans produced salmon-coloured colonies surrounded by wide gelase fields; the diameter of the colonies generally did not exceed $1 \mathrm{~cm}$. The depressions formed on the agar surface were usually not so deep as those formed by $C$. fermentans var. agarovorans; although the organisms migrated into the agar, this tendency was less marked than with $C$. fermentans var. agarovorans. The agar did not become completely liquefied as in anaerobic cultures. C. salmonicolor var. agarovorans sometimes exhibited spreading growth on aerobic agar plates. Some colonies were apt to present a swarming edge, others a smooth sharply defined circumference. Either colony type yielded both forms on replating. A similar case of colony dimorphism was observed by Stanier (1942) with Sporocytophaga myxococcoides. Unlike C. fermentans var. agarovorans, C. salmonicolor var. agarovorans generally showed a decreased degree of swarming on a medium with $2 \%(\mathrm{w} / \mathrm{v})$ agar; crater formation was then slightly retarded.

Cytophaga salmonicolor, like C. salmonicolor var. agarovorans, formed salmoncoloured colonies with a maximum diameter of $1 \mathrm{~cm}$. They were either flat and spreading (Pl. 1, fig. 7) or convex with a smooth edge. When grown on a $1 \%(\mathrm{w} / \mathrm{v})$ agar-medium, the organisms penetrated to a limited extent into the agar, and the colonies occasionally sank slightly into the agar. Gran's test was weakly positive (max. diam. of zone around colonies $0.5 \mathrm{~mm}$.), but the agar around the colonies was never depressed or softened, as was the case with the two other types. Colonies never appeared sunken on a medium with $2 \%(\mathrm{w} / \mathrm{v})$ agar. Fermentation tests carried out with washed agar as a carbon source showed thatC. salmoni color did not ferment agar.

The above-mentioned observations lead to the conclusion that Cytophaga salmonicolor was unable to grow with agar as sole $\mathrm{C}$ source. Colonies of aerobically grown $C$. salmonicolor were catalase positive. C. salmonicolor var. agarovorans and 
C. fermentans var. agarovorans sometimes showed a negative catalase reaction when grown on a medium containing $1 \%(\mathrm{w} / \mathrm{v})$ agar, even when $\mathrm{CaCO}_{3}$ was included. When $2 \%(\mathrm{w} / \mathrm{v})$ agar was used the tendency to penetrate into the agar was less pronounced; in this case the agar-decomposing cytophagas generally gave a positive catalase reaction.

\section{Inhibitory effect of glucose and galactose}

Under semi-anaerobic conditions (stab cultures in agar media without $\mathrm{Na}_{2} \mathrm{~S}$ and without paraffin seal), or on aerobic plates, glucose and galactose markedly inhibited growth of Cytophaga fermentans var. agarovorans and C. salmonicolor var. agarovorans. Only a minute fraction of the inoculated viable organisms produced colonies in or on the sugar-containing substrate, and these colonies appeared where the inoculum was densest. These colonies were similar to those which grow on sugarfree media, and they decomposed agar at nearly the same rate. The inhibition by glucose and galactose could not be attributed to the formation of toxic products during autoclaving; when sterilized by Seitz filtration and added to the agar after this had been cooled to $40^{\circ}$, solutions of these sugars exerted the same effect. The growth of $C$. salmonicolor on agar media was hardly affected by adding glucose; but the addition of $0 \cdot 1 \%(\mathrm{w} / \mathrm{v})$ galactose strongly inhibited the development of the organism under aerobic conditions. A similar behaviour was reported for the agardecomposing $C$. sensitiva (Humm, 1946), which did not grow on agar media with added $\mathbf{0 . 2} \%(\mathrm{w} / \mathrm{v})$ glucose or starch; and for the cellulose-decomposing Sporocytophaga myxococcoides, which also was prevented from growing by $0.2 \%(\mathrm{w} / \mathrm{v})$ glucose (Kaars Sijpesteyn \& Fåhraeus, 1949). The mechanism of this striking inhibition is still obscure.

\section{The nature of the fermentation}

Methods. Fermentations were carried out in Hall flasks or in an apparatus previously described (Veldkamp, 1960); the latter apparatus was modified to maintain a constant $\mathrm{pH}$ value during the fermentation by means of an automatic titrator type TTT1 (Radiometer, Copenhagen, Denmark). For this purpose the all-glass fermentation vessel was provided with ground glass sockets for the glass- and calomel electrodes and alkali inlet. During the fermentation sterile $\mathrm{NaOH}$ was added from a burette operated by a magnetic valve.

The electrodes were sterilized chemically using a commercial iodophor solution (JO 127; Amsterdamse Kininefabriek, Amsterdam, Netherlands) which contains $1.5 \%$ active iodine. The electrodes were immersed for $20 \mathrm{~min}$. in a $1 / 500$ dilution of the iodophor solution and then washed with sterile water.

The experiments were made at $30^{\circ}$ in an oxygen-free nitrogen atmosphere, with a mineral medium which in addition to the usual salts contained $(\%, w / v) 0 \cdot 1$, $\mathrm{NaHCO}_{3} ; 0.05, \mathrm{Na}_{2} \mathrm{~S} .9 \mathrm{H}_{2} \mathrm{O}$; adjusted to $\mathrm{pH} 7$.

For the fermentations with agar as carbon source, $\mathbf{0} \cdot 3 \%(\mathrm{w} / \mathrm{v})$ Difco agar was used (this had been carefully washed with distilled water for 7 days); $0 \cdot 1 \%(w / v)$ each of yeast extract, corn steep liquor and nutrient broth were included. Control experiments showed that only a trace of acid was formed when the agar was omitted from the medium. For hexose fermentations $0.1 \%(\mathrm{w} / \mathrm{v})$ yeast extract and either $0 \cdot 1-$ $\mathbf{0 . 2} \%$ (fermentations in Hall flasks) or $\mathbf{1} \%$ sugar (fermentations at constant $\mathrm{pH}$ ) were added to the basal medium. The sugars were sterilized separately as concen- 
trated aqueous solutions. The analyses of fermentation products were performed as previously described (Veldkamp, 1960).

The dry weight of the slimy cell material was determined as follows. At the end of the fermentation 3 volumes of ethanol were added to a sample of the culture liquid; the resulting stringy precipitate was centrifuged down, washed twice with $95 \%(w / v)$ ethanol in water, then dried in vacuo at $45^{\circ}$ and weighed. This material was considered to have the empirical formula $\left(\mathrm{CH}_{2} \mathrm{O}\right)$, an approximation supported by studies of bacterial assimilation (see Clifton, 1951).

Results. The results of the fermentations with galactose as carbon and energy source are shown in Table 1 which shows that acetic, propionic and succinic acids were the major products of galactose fermentation by all the organisms tested. Cytophaga salmonicolor and C. salmonicolor var. agarovorans formed a considerable amount of formic acid. Fermentations with washed Difco agar as substrate showed that $C$. salmonicolor did not form acid, whereas vigorous acid-production was observed with cultures of $C$. salmonicolor var. agarovorans and $C$. fermentans var. agarovorans, with a concomitant decrease in $\mathrm{pH}$ value from $7 \cdot 0$ to $5 \cdot 4$. The same acids were found in agar and galactose fermentations.

Table 1. Acids produced during fermentation of galactose in Hall flasks by various cytophagas

\begin{tabular}{lccc}
\multicolumn{1}{c}{ Product } & C. salmonicolor & $\begin{array}{c}\text { C. salmonicolor } \\
\text { var. } \\
\text { agarovorans }\end{array}$ & $\begin{array}{c}\text { C. fermentans } \\
\text { var. } \\
\text { agarovorans }\end{array}$ \\
Formic acid & mM product/mm galactose fermented \\
Acetic acid & $0 \cdot 50$ & $0 \cdot 33$ & 0 \\
Propionic acid & $0 \cdot 42$ & $0 \cdot 26$ & $0 \cdot 27$ \\
Succinic acid & $0 \cdot 26$ & $0 \cdot 23$ & $0 \cdot 48$ \\
& $0 \cdot 32$ & $0 \cdot 38$ & $0 \cdot 13$
\end{tabular}

A more detailed analysis of the fermentation products formed by Cytophaga salmonicolor var. agarovorans from glucose is presented in Table 2. This fermentation was run at $\mathrm{pH} 7 \cdot 0$; under these conditions $1 \%$ glucose was completely consumed. From Table 2 it can be seen that acetic, propionic and succinic acids were the major fermentation products. In addition, considerable amounts of $\mathrm{CO}_{2}$ and $\mathrm{H}_{2}$ were formed; these were also formed by $C$. salmonicolor, but not by $C$. fermentans var. agarovorans. Small amounts of formic and lactic acids and of ethanol were found as end products of the glucose fermentation by $C$. salmonicolor var. agarovorans. As much as $21 \%$ of the glucose consumed was converted to cell material (bacterial cells and slime). According to Bachmann (1955), 15-25\% of glucose consumed during fermentation of $C$. fermentans was converted to alcohol-precipitable cell material. The fermentation products formed by this organism are the same as those produced by $C$. fermentans var. agarovorans. It appears that all facultatively anaerobic cytophagas so far studied exhibit a propionic acid type of fermentation. C. succinicans, which Anderson \& Ordal $(1961 a, b)$ showed to produce formic, acetic, and succinic acids but not propionic acid, may be considered as a variant lacking the ability to decarboxylate succinate. A similar connexion is encountered in the lactate and sugar fermentations by Propionibacterium, Veillonella and Ruminococcus species, respectively. 
Table 2. Fermentation of glucose at $\mathrm{pH} 7 \cdot 0$ by Cytophaga salmonicolor var. agarovorans

\begin{tabular}{|c|c|c|}
\hline Product & $\begin{array}{c}\mathrm{mm} \text { product } / \mathrm{mm} \\
\text { glucose } \\
\text { fermented }\end{array}$ & $\begin{array}{c}\text { mg. atom } \\
\text { carbon }\end{array}$ \\
\hline $\mathrm{CO}_{2}$ & $0 \cdot 32$ & $0 \cdot 32$ \\
\hline $\mathbf{H}_{2}$ & $0 \cdot 44$ & - \\
\hline Ethanol & $0 \cdot 16$ & $0 \cdot 32$ \\
\hline Formic acid & $0 \cdot 05$ & 0.05 \\
\hline Acetic acid & $0 \cdot 38$ & $0 \cdot 76$ \\
\hline Propionic acid & $0 \cdot 31$ & 0.93 \\
\hline Succinic acid & $0 \cdot 33$ & $1 \cdot 32$ \\
\hline Lactic acid & $0 \cdot 09$ & $\mathbf{0 \cdot 2 7}$ \\
\hline Cell material and slime, as $\left(\mathrm{CH}_{2} \mathrm{O}\right)$ & $1 \cdot 28$ & $1 \cdot 28$ \\
\hline Total mg. atom C & - & $5 \cdot 25$ \\
\hline Carbon recovery \% & $87 \cdot 5$ & - \\
\hline Redox index & $0 \cdot 96$ & - \\
\hline
\end{tabular}

Taxonomy

The following characters exhibited by our organisms indicate that they must be considered as members of the genus Cytophaga (Stanier, 1942): flexing and gliding motility, low-refractility, ability to swarm across an agar surface, absence of microcysts and fruiting bodies. All the strains examined were facultative anaerobes found in marine environments, characters which they have in common with $C$. fermentans (Bachmann, 1955). C. salmonicolor differs from $C$. fermentans by the formation of a red pigment and ability to produce formic acid, $\mathrm{CO}_{2}$ and $\mathrm{H}_{2}$ during fermentation of carbohydrates. Our $C$. fermentans var. agarovorans differs from $C$. fermentans by its ability to grow with agar as sole $\mathrm{C}$ source. A similar difference exists between $C$. salmonicolor and C. salmonicolor var. agarovorans. Since ability to decompose complex polysaccharides is an important characteristic in the classification of the myxobacteria, and since agar decomposition is associated with the appearrance of cultures on or in agar, our agar-decomposing cytophagas are here described as varieties of $C$. fermentans and $C$. salmonicolor.

\section{Description of Cytophaga salmonicolor}

Morphology : flexible weakly refractile, slender rods with rounded ends. Organisms vary in length from 2 to $30 \mu$; average about $6 \mu$. Width $0 \cdot 3-0 \cdot 5 \mu$. Gliding motility in young cultures. Coccoid involution forms common in old cultures. Branched organisms do not occur. Star-shaped aggregates of actively flexing organisms common in liquid cultures. Gram-negative.

Growth on agar plate: colonies on medium with $1 \%$ agar and low nutrient concentration are salmon-coloured; may or may not show spreading growth across surface. Colonies sometimes slightly sunken into agar, but the agar around colonies never depressed or softened. On $2 \%$ agar colonies never sunken into agar.

Agar shake culture: small, pink, spherical or disk-shaped colonies which do not attack agar. Apparently grows at expense of added nutrients to agar medium.

Agar stab culture: grows only when glucose or complex nitrogenous nutrients are added. Diameter of stab in $1 \%$ agar does not exceed $2 \mathrm{~mm}$. 
Gelatin stab: very slow crateriform liquefaction.

Fermentation: the following substrates fermented: arabinose, xylose, glucose, galactose, mannose, fructose, sucrose, lactose, maltose, cellobiose, trehalose, raffinose, inulin, starch. Not fermented: rhamnose, sorbose, mannitol, sorbitol, agar. Chitin not attacked aerobically. Products of glucose fermentation: formic, acetic, propionic, succinic, lactic acids, $\mathrm{CO}_{2}, \mathrm{H}_{2}$, traces of ethanol.

Nitrogen sources: ammonium salts, nitrates, yeast extract, nutrient broth, Casamino acids.

Growth factors : grows in mineral glucose medium; heavier and more rapid growth occurs in the presence of a vitamin mixture; carbon dioxide an absolute requirement for growth.

Catalase produced.

Salt concentration range: $\mathbf{1} \cdot \mathbf{0}-\mathbf{3} \cdot 0 \%(\mathrm{w} / \mathrm{v}) \mathrm{NaCl}$.

Facultatively anaerobic.

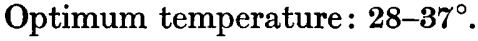

Source: marine mud.

Habitat: probably decaying seaweeds.

Description of Cytophaga salmonicolor var. agarovorans

Morphology: similar to C. salmonicolor.

Growth on agar plate: colonies on a medium with $1 \%$ agar and low nutrient concentration are salmon-coloured, sunken into the agar; may or may not show swarming across agar surface. Colonies surrounded by wide translucent gelase fields in which agar is depressed and softened; agar is not completely liquefied. Formation of depressions in agar slightly retarded when $2 \%$ agar used.

Agar shake culture: in medium with $1 \%$ agar, pink spherical colonies formed, up to $1 \mathrm{~cm}$. diam.; agar in area occupied by colony completely liquefied.

Agar stab culture: in medium with $1 \%$ agar as energy source diffuse growth with complete liquefaction of agar; diameter of stab 4-10 mm. Growth in 2\% agar considerably less diffuse.

All other characteristics are similar to those encountered with $C$. salmonicolor with the exception of fermentation test with washed agar as substrate (positive).

Source: marine mud.

Habitat: probably decaying seaweeds.

Description of Cytophaga fermentans var. agarovorans

Morphology: very similar to C.fermentans and C. salmonicolor.

Growth on agar plate: colonies on medium with $1 \%$ agar and low nutrient concentration greyish; centre of colony may become cream to pale yellow. Colonies largely subsurface and form deep craters in agar; they are surrounded by wide gelase fields in which agar becomes depressed, translucent and softened. Swarming growth across agar surface may occur, although generally colonies have a sharp smooth edge. On $2 \%$ agar media, colonies flat spreading nearly colourless translucent. In older parts of colonies organisms may tend to accumulate in drop-like masses which contain normal vegetative organisms. Depressions formed in $2 \%$ agar very shallow. 
Agar shake culture: in medium with $1 \%$ agar, greyish to cream spherical colonies which attain a diameter of $1 \mathrm{~cm}$; agar is softened.

Agar stab culture: in medium with $1 \%$ agar as energy source diffuse growth causing softening of agar; stabs attain diameter of 4-10 mm.; growth in $2 \%$ agar considerably less diffuse.

Gelatin stab culture: slow stratiform liquefaction.

Fermentation: the following substrates fermented: arabinose, xylose, rhamnose, glucose, galactose, mannose, fructose, mannitol, sorbitol, sucrose, lactose, maltose, cellobiose, raffinose, inulin, starch, agar. Not fermented: sorbose, trehalose. Chitin not attacked aerobically. Products of glucose fermentation are: acetic, propionic and succinic acids.

Nitrogen sources: ammonium salts, nitrates, yeast extract, nutrient broth, Casamino acids.

Growth factors: not needed when grown anaerobically or semi-anaerobically with hexoses as carbon source. Addition of a vitamin mixture causes more rapid and abundant growth, especially when cultivated under semi-anaerobic conditions.

Carbon dioxide an absolute growth requirement.

Catalase produced.

Salt concentration range: $\mathbf{1} \cdot \mathbf{0}-\mathbf{3} \cdot \mathbf{0} \%(\mathrm{w} / \mathrm{v}) \mathrm{NaCl}$.

Facultatively anaerobic.

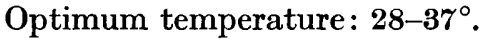

Source: marine mud.

Habitat: probably decaying seaweeds.

Cultures of the described cytophagas have been deposited in the National Collection of Industrial bacteria, Torrey Research Station, Aberdeen, Great Britain.

I am greatly indebted to Dr June Lascelles who provided cultures of the cytophagas here described and to Dr W. Clark for supplying C.fermentans (ATCC no. 12470). The assistance of Miss A. van Mourik is gratefully acknowledged. My thanks are due to Professor C. B. van Niel and to Dr June Lascelles for reading and improving the text of this paper.

\section{REFERENCES}

Anderson, R. L. \& Ordal, E. J. (1961 a). Cytophaga succinicans Sp.N., a facultatively anaerobic, aquatic myxobacterium. J. Bact. 81, 130.

Anderson, R. L. \& Ordal, E. J. (1961b). $\mathrm{CO}_{2}$-dependent fermentation of glucose by Cytophaga succinicans. J. Bact. 81, 139.

Araki, C. (1956). Structure of the agarose constituent of agar. Bull. chem. Soc. Japan, 29, 543.

Arakr, C. \& AraI, K. (1956). Studies on the chemical constitution of agar-agar. XVIII. Isolation of a new crystalline disaccharide by enzymatic hydrolysis of agar-agar. Bull. chem. Soc. Japan, 29, 339.

Bachmann, B. J. (1955). Studies on Cytophaga fermentans, n.sp., a facultatively anaerobic lower myxobacterium. J. gen. Microbiol. 13, 541.

BARKer, H. A. (1936). On the biochemistry of the methane fermentation-Studies upon the methane-producing bacteria. Arch. Mikrobiol. 7, 420.

Cumpron, C. E. (1951). In Bacterial Physiology, ed. C. H. Werkman and P. W. Wilson, p. 531. New York: Academic Press Inc.

Gran, H. H. (1902). Studien über Meeresbakterien. II. Über die Hydrolyse des Agars durch ein neues Enzym, die Gelase. Bergens Mus. Aarb. 2, 1-16. 
Humm, H. J. (1946). Marine agar-digesting bacteria of the south Atlantic coast. Bull. Duke Univ. Mar. Sta. 3, 45.

KaArs SiJpesteyn, A. \& Fåhraeus, G. (1949). Adaptation of Sporocytophaga myxococcoides to sugars. J. gen. Microbiol. 3, 224.

Kohlmiller, JUN. E. F. \& GeST, H. (1951). A comparative study of the light and dark fermentations of organic acids by Rhodospirillum rubrum. J. Bact. 61, 269.

MorI, T. (1953). Seaweed polysaccharides. Advanc. carbohyd. Chem. 8, 316.

STANIER, R. Y. (1941). Studies on marine agar-digesting bacteria. J. Bact. 42, 527 .

STANier, R. Y. (1942). The cytophaga group: a contribution to the biology of myxobacteria. Bact. Rev. 6, 143.

Stanier, R. Y. (1947). Studies on nonfruiting myxobacteria. I. Cytophaga johnsonae, n.sp., a chitin-decomposing myxobacterium. J. Bact. 53, 297.

VELDKAMP, H. (1960). Isolation and characteristics of Treponema zuelzerae nov. spec., an anaerobic, free-living spirochete. Antonie van Leeuwenhoek J. Microbiol. Serol. 26, 103.

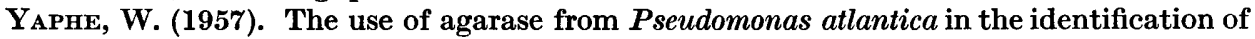
agar in marine algae (Rhodophyceae). Canad. J. Microbiol. 3, 987.

\section{EXPLANATION OF PLATES}

Plate 1

Fig. 1. Cytophaga fermentans var. agarovorans. Agar shake culture; spherical colonies in $1 \%$ agar medium with $0.1 \%$ each of yeast extract, corn steep liquor and nutrient broth; age 9 days.

Fig. 2. C. salmonicolor. Agar shake culture; small spherical colonies grown in $1 \%$ agar medium with $0.1 \%$ each of yeast extract, corn steep liquor, and nutrient broth; age 9 days.

Fig. 3. C. fermentans var. agarovorans. Stab culture after 5 days' cultivation at $30^{\circ}$ in mineral medium with $1 \%$ agar and $0.1 \%$ yeast extract.

Fig. 4. C. salmonicolor var. agarovorans. Stab culture after 5 days' cultivation at $30^{\circ}$ in mineral medium with $1 \%$ agar and $0.1 \%$ yeast extract.

Fig. 5. C. salmonicolor var. agarovorans. Phase-contrast photomicrograph of living cells from anaerobic stab culture. $\times \mathbf{2 3 4 0}$.

Fig. 6. C. fermentans var. agarovorans. Coccoid involution forms from agar shake culture. Phase contrast. $\times 1574$.

Fig. 7. C. salmonicolor. Colonies showing flat, spreading growth on $1 \%$ agar medium.

\section{Plate 2}

Fig. 8. Cytophaga fermentans var. agarovorans. Aerobic plate culture with mineral medium containing $1 \%$ agar and $0.1 \%$ each of yeast extract, corn steep liquor, and nutrient broth. Colonies deeply sunken into agar and surrounded by zone in which agar is softened and depressed. Age one week.

Fig. 9. C. fermentans var. agarovorans. Same plate showing gelase fields after flooding with I-KI solution. 
Journal of General Microbiology, Vol. 26, No. 2

Plate 1

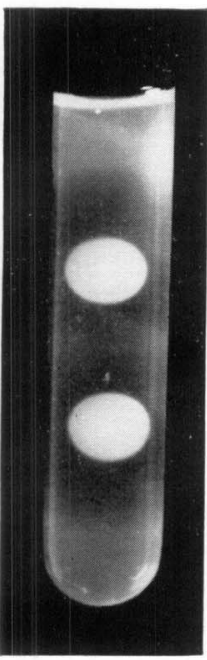

Fig. 1

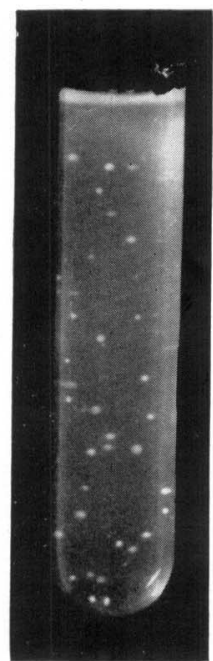

Fig. 2

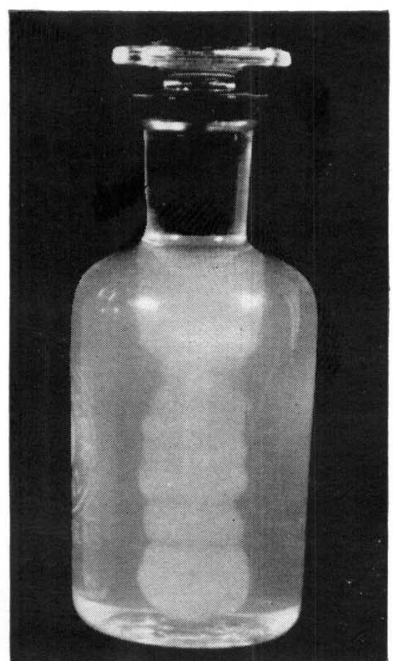

Fig. 3

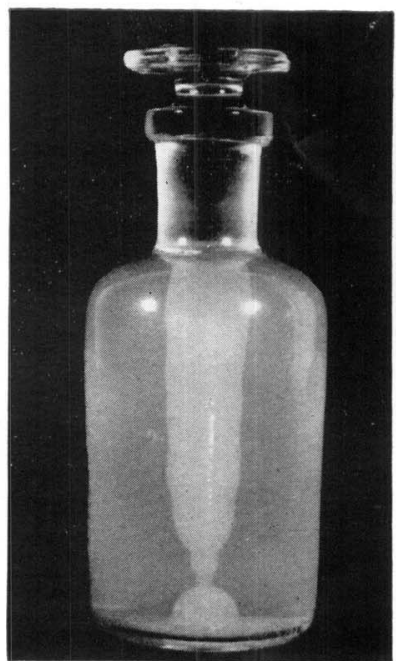

Fig. 4

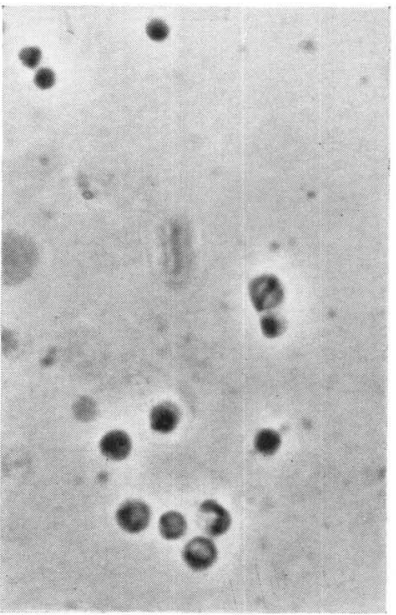

Fig. 6

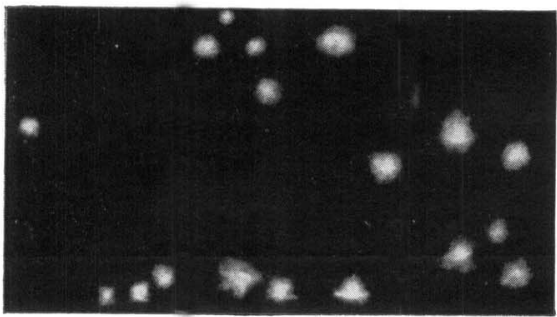

Fig. 7

H. VELDKAMP

(Facing p. 342) 
Journal of General Microbiology, Vol. 26, No. 2

Plate 2

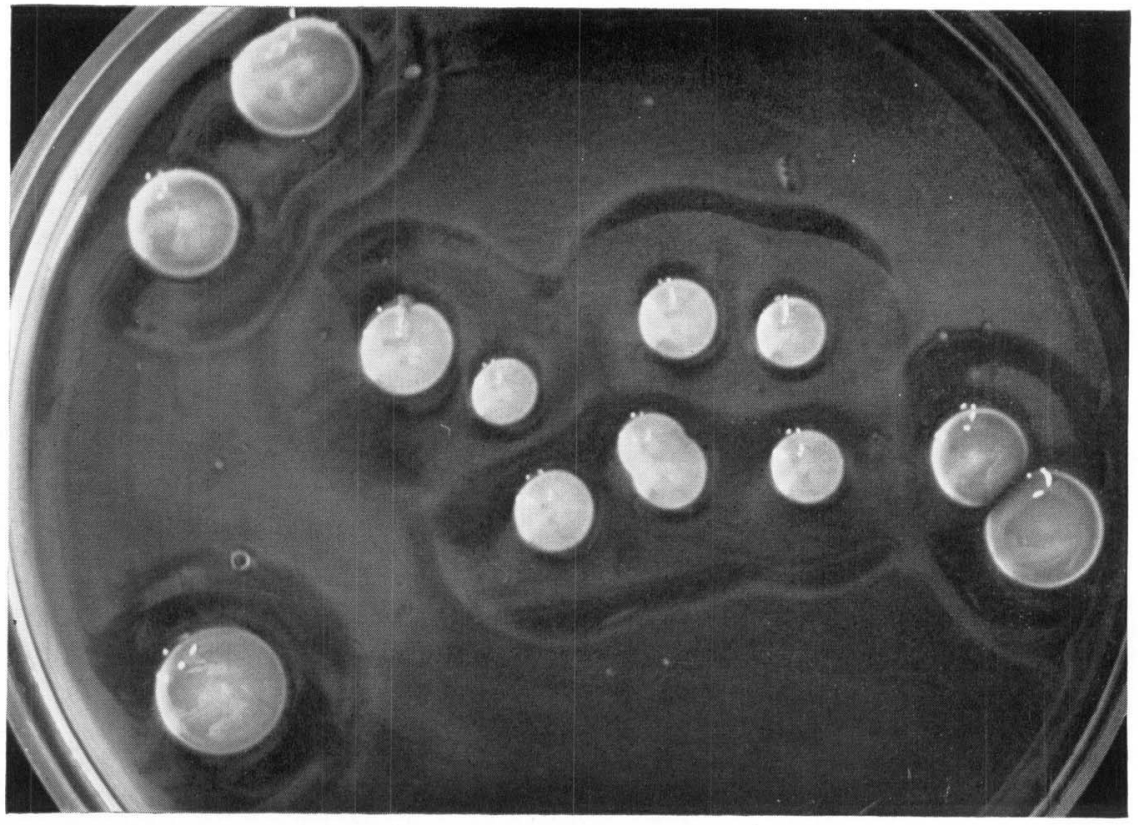

Fig. 8

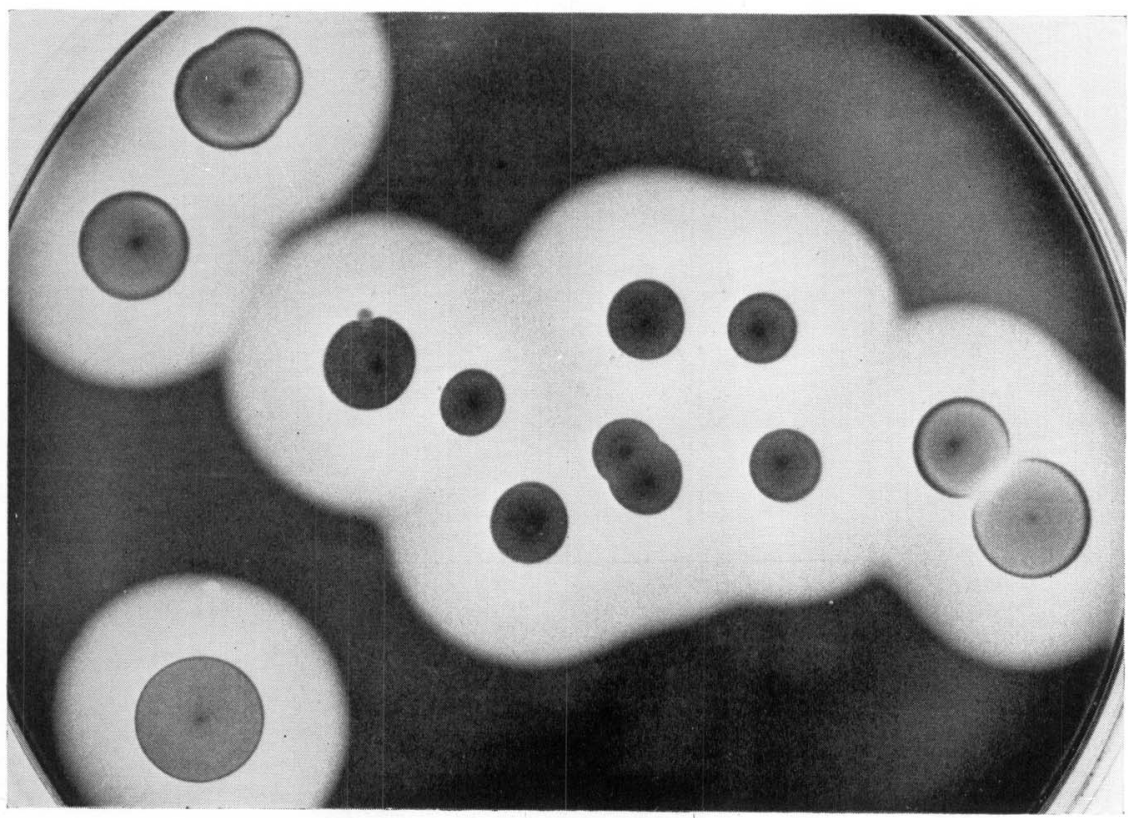

Fig. 9

H. VELDKAMP 